\title{
An Exploration of the Oryza sativa L. Cyanidin-3-glucoside on the Cognitive Function in Older Adults with Subjective Memory Impairment
}

\author{
Soo Hyun Joo ${ }^{1,6}$, Changtae Hahn ${ }^{2,6}$, Hyun Kook Lim ${ }^{3,6}$, Kee Dong Yoon ${ }^{4,6}$, \\ Shin Hee Yoon ${ }^{5,6}$, and Chang Uk Lee ${ }^{1,6} \bowtie$ \\ ${ }^{1}$ Department of Psychiatry, Seoul St. Mary's Hospital, College of Medicine, The Catholic University of Korea, Seoul, Republic of Korea \\ 2Department of Psychiatry, Daejeon St. Mary's Hospital, College of Medicine, The Catholic University of Korea, Daejeon, Republic of Korea \\ ${ }^{3}$ Department of Psychiatry, Yeouido St. Mary's Hospital, College of Medicine, The Catholic University of Korea, Seoul, Republic of Korea \\ ${ }^{4}$ College of Pharmacy and Integrated Research Institute of Pharmaceutical Sciences, The Catholic University of Korea, Bucheon, Republic of Korea \\ ${ }^{5}$ Department of Physiology, College of Medicine, The Catholic University of Korea, Seoul, Republic of Korea \\ ${ }^{6}$ Catholic Agro-Medical Center, The Catholic University of Korea, Seoul, Republic of Korea
}

Objective Cyanidin-3-glucoside (C3G), is a component of anthocyanin, have been considered to positively influence cognition and be beneficial for the prevention and treatment of dementia. We aimed to assess the safety and efficacy of cyanidin-3-glucoside-rich Oryza sativa L. (black rice) extract on cognitive function.

Methods A 12-weeks double-blind randomized, placebo controlled trial assessed safety and cognitive outcomes in participants with subjective memory impairment $(n=48)$ following consumption of 6 black rice extract capsules or a placebo. Cognitive function was assessed using the ADAS-cog and the CERAD-K. Subjective memory impairment also assessed. Safety was assessed by hematologic blood test, urine analysis, and participant reports of adverse events.

Results There was significant improvement on subjective memory in intervention group. There was no statistically significant difference in objective cognitive outcomes following 12 weeks of consuming black rice extract. ADAS-cog scores, however, trended toward improvement in the intervention group compared to the placebo group. There was no adverse event.

Conclusion Although significant improvement in objective cognitive function was not proved, we found that C3G-rich Oryza sativa L. extract improves subjective memory in this study. Therefore the results may be informative of the possible effectiveness of the C3G-rich Oryza sativa L. on cognitive function.

Psychiatry Investig 2019;16(10):759-765

Key Words Oryza sativa L, Cyanidin-3-glucoside, Cognitive function, Safety.

\section{INTRODUCTION}

The number of dementia patients is rapidly increasing worldwide, along with the social cost of caring for these patients. However, there is no disease-modifying medication for this disease. Therefore, prevention of dementia is considered to be more important. Recently, interest in inflammation and

Received: April 19, 2019 Revised: May 28, 2019

Accepted: June 17, 2019

$\triangle$ Correspondence: Chang Uk Lee, MD, PhD

Department of Psychiatry, Seoul St. Mary's Hospital, College of Medicine, The Catholic University of Korea, 222 Banpo-daero, Seocho-gu, Seoul 06591, Republic of Korea

Tel: +82-2-2258-6082, Fax: +82-2-594-3870, E-mail: jihan@catholic.ac.kr

(a) This is an Open Access article distributed under the terms of the Creative Commons Attribution Non-Commercial License (https://creativecommons.org/licenses/bync/4.0) which permits unrestricted non-commercial use, distribution, and reproduction in any medium, provided the original work is properly cited. oxidative stress of dementia pathology has increased. $.^{1-3} \mathrm{Di}-$ etary approaches have an especially strong interest because these are considered to be safe and effective methods for maintenance or improvement of cognitive function.

Cyanidin-3-glucoside (C3G), is a component of anthocyanin, which is a potent natural antioxidant. C3G has been reported to have a neuroprotective effects against neuronal cell death in vitro ${ }^{4-6}$ and in vivo. ${ }^{7.8}$ Several studies utilizing anthocyanin-rich fruit juice consumption for 12-16 weeks have reported improvements in either a single or multiple cognitive outcomes. ${ }^{9-11}$ Similarly, interventions of utilizing cocoa for 8-12 weeks reported improvements in either a single, or multiple, cognitive outcomes on neuropsychological variables..$^{12-14}$ However, one study utilizing dark chocolate and cocoa for 6 weeks did not show any cognitive improvement. ${ }^{15}$ 
Oryza sativa L. (black rice) has been widely consumed in Asian countries. Recently, it has received much attention because it contains large amount of anthocyanin, especially C3G, however no known clinical studies examining the association about black rice and cognitive effects have been conducted. Existing animal models studies demonstrate the antioxidant and anti-inflammatory ${ }^{16-19}$ in-vitro and in-vivo properties of Oryza sativa L., successful in reducing cancer growth, ${ }^{20-22}$ and maintaining control of hypercholoesterolemia. ${ }^{23-25}$ Nakamura et al. ${ }^{26}$ demonstrated the potential beneficial effects of Oryza sativa L. in a mice model of Alzhimer's disease. Similarly, our team in the Catholic Agro-Medical Center found that C3G inhibits glutamate-induced $\mathrm{Zn} 2 \mathrm{p}$ signaling and neuronal cell death in cultured rat hippocampal neurons. ${ }^{6}$ Based on this previous study, we aimed to assess the safety and efficacy of C3G-rich Oryza sativa L. extract on cognitive function in older adults with subjective memory impairment.

\section{METHODS}

\section{Participants}

Participants were recruited from Seoul St. Mary's Hospital and St. Vincent Hospital outpatient clinics in South Korea. Participants were aged 50 years or older with subjective memory impairment, defined by a complaint(s) made by individuals with memory impairment symptoms but no clear impairment on objective psychometric testing. Participants with no cognitive impairment on any Korean version of the Consortium to Establish a Registry for Alzheimer's disease (CERAD-K) scales and who scored 0 on the clinical dementia rating (CDR) score were included. Participants who have organic brain disorder detected by brain magnetic resonance imaging (MRI) were excluded. Participants with active or clinically significant neurological, cardiovascular, respiratory, hepatic, gastrointestinal, renal or urological, endocrine, or hematological diseases were excluded. We also excluded participants who scored higher than a 7 on the Hamilton Rating Scale for Depression (HAM-D).

This study protocol (KC14HNSE0312) was approved by the Institutional Review Boards of St. Mary's Hospital and St. Vincent Hospital. This study protocol was registered as a clinical trial (https://cris.nih.go.kr:KCT0002798) through the Clinical Research Information Service (CRIS), Korea Centers for Disease Control and Prevention, Ministry of Health and Welfare (Republic of Korea). All participants voluntarily attended this study and gave written informed consent to participate.

\section{Study design and procedure}

The present study comprised a parallel randomized controlled clinical trial.
Participants were randomized to intervention or placebo group by computerized randomization. Randomization assignment was conducted using computer-generated random numbers. Randomization and allocation were carried out by a trained midwife and the outcome was masked from the researcher and subjects until the main analyses were completed.

Oryza sativa L. concentrate was produced by extracting C3G from the black rice by using countercurrent chromatography (HPCCC) coupled with reversed-phase medium pressure liquid chromatography (RP MPLC) method. ${ }^{27}$ The material and amount of $500 \mathrm{mg}$ black rice extract capsule are $50 \%$ Oryza sativa L. extract powder, $40 \%$ crystalline cellulose, $9 \%$ glucose, and 1\% malic acid. The material and amount of $500 \mathrm{mg}$ placebo is $100 \%$ crystalline cellulose. The placebo and Oryza sativa L. extract capsules were identical in size and appearance. During 12 weeks, participants ingested 2 capsules three times a day (6 capsules/d total), with water. Total amount of daily C3G intake was $19.08 \mathrm{mg}$. No change to regular diet was advised.

Before the initiation of the treatment phase, participants underwent a physical examination, brain MRI, hematologic laboratory test, urine analysis and APOE genotyping. A single researcher interviewed the participants for demographic characteristics and checked vital signs, height, and weight. Subjective Memory Complaints Questionnaire (SMCQ), a brief self-rated questionnaire to report their memory problems in general and in daily living, which consists of 14 items and the highest possible total score is 14 points was conducted. ${ }^{28}$ Cognitive function was assessed using the Alzheimer's Disease Assessment Scale-cognitive subscale (ADAS-cog), and the CERAD-K. CERAD-K consisted of verbal fluency (VF), the 15-item Boston Naming Test (BNT), the Mini Mental Status Examination (MMSE), word list memory (WLM), constructional praxis (CP), word list recall (WLR), word list recognition (WLRc), constructional recall (CR), trail making A and B. ADAS-cog is evaluated on a negatively rated scale, meaning lower the score, the better the cognitive function, as is the trail making test of the CERAD-K (less the time, it takes to complete, the better the cognitive function).

After 4 weeks of C3G-rich Oryza sativa L. extract or placebo intake, a physical examination, vital signs, drug compliance, and adverse events were assessed. After 12 weeks, a physical examination, vital signs, height, and weight, a hematologic laboratory test, urine analysis, drug compliance, adverse events, SMCQ and cognitive function were assessed. Only the data of participants reaching an intervention compliance threshold of $\geq 70 \%$ were included in the analysis.

\section{Statistical analyses}

All analyses were performed with SPSS version 24 (IBM 


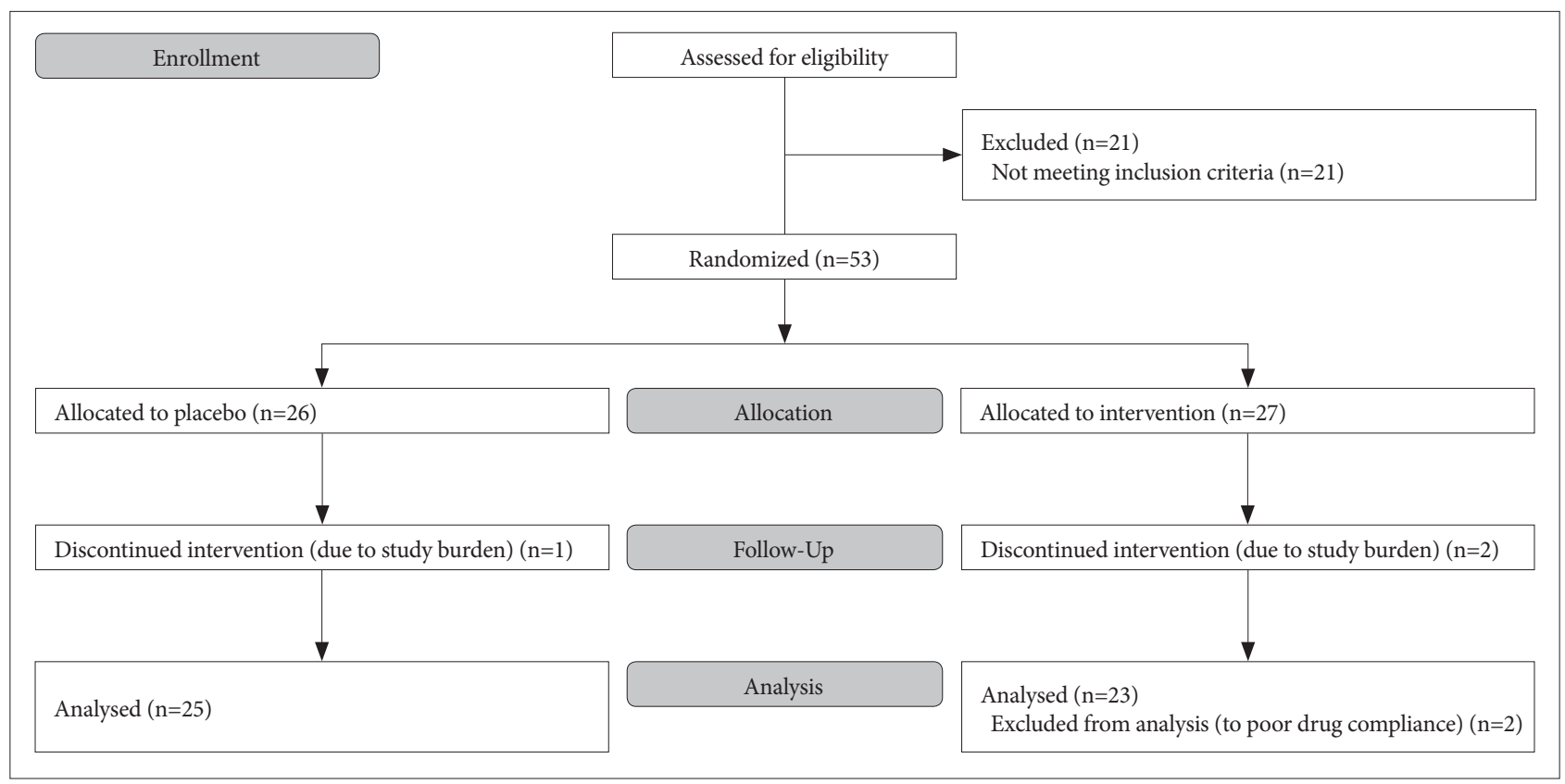

Figure 1. Flow diagram of the progress through the phases of a parallel randomized trial of two groups (that is, enrollment, intervention allocation, follow-up, and data analysis).

Corp., Armonk, NY, USA). Baseline characteristics were described by mean \pm standard deviation or frequency (percentage). Baseline characteristics of participants between placebo and intervention group were compared by Student's t-test, Fisher's exact test, or chi-square test. A repeated measure ANOVA was used to analyze to the difference between placebo and intervention groups at baseline and 12 weeks of lipid profiles, blood pressure, and scores of neuropsychological test.

\section{RESULTS}

\section{Number and baseline characteristics of participants}

A trial flow diagram is provided in Figure 1. 74 individuals were screened for eligibility and 21 were excluded due to criterial listed above. 53 participants were randomized and assigned to the intervention group $(\mathrm{n}=27)$ or the control group $(\mathrm{n}=26)$. Three participants withdrew from the study due to study burden. After completing the clinical study, we excluded 2 participants' data from statistical analysis due to poor drug compliance, yielding a total of 48 participants for analysis. Participants' baseline characteristics were shown Table 1. There were no differences between groups for age, sex, weight, year of education, family history of dementia, or APOE4 gene at baseline.

\section{Blood pressure and lipid profiles}

The repeated measure ANOVA showed no significant differences in blood pressure and blood lipid profile, including total cholesterol, triglyceride, HDL, and LDL in the interven-
Table 1. Baseline characteristics of participants by group

\begin{tabular}{|c|c|c|c|c|}
\hline & $\begin{array}{c}\text { All } \\
(\mathrm{N}=48)\end{array}$ & $\begin{array}{l}\text { Placebo } \\
\text { group } \\
(\mathrm{N}=23)\end{array}$ & $\begin{array}{c}\text { Intervention } \\
\text { group } \\
(\mathrm{N}=25)\end{array}$ & $\mathrm{p}$ value \\
\hline Age (y & $63.88(7.59)$ & $62.70(6.84)$ & $64.96(8.20)$ & 0.31 \\
\hline Sex (female) (\%) & $32(66.67)$ & $15(65.22)$ & $17(68.0)$ & 0.84 \\
\hline Weight (kg) & $62.51(9.09)$ & $64.20(11.43)$ & $60.96(6.08)$ & 0.22 \\
\hline $\begin{array}{l}\text { Education } \\
\text { (years) }\end{array}$ & $10.56(3.75)$ & $11.17(4.08)$ & $10.00(3.42)$ & 0.28 \\
\hline $\begin{array}{l}\text { Family history } \\
\text { of dementia (\%) }\end{array}$ & 6.67) & $6(2$ & 2( & 0.13 \\
\hline APOE4 gene (\%) & $5(10.42)$ & $2(8.70)$ & $3(12.0)$ & 1.00 \\
\hline
\end{tabular}

Data are presented as the means (SD) or numbers (\%)

tion group compared to in placebo group (Table 2).

\section{Cognitive function outcomes and subjective questionnaire}

There was no significant improvement in cognitive function by CERAD-K score. However, there was a trend for improvement in ADAS-cog score in the intervention group (placebo: $12.48 \rightarrow 11.70$, intervention group: $12.96 \rightarrow 11.20$, $\mathrm{p}=0.266$ ). After excluding participant with APOE4 gene $(n=5)$, the trend for improvement in ADAS-cog score was strengthened in the intervention group than control group (placebo: $12.38 \rightarrow 11.67$, intervention group: $13.00 \rightarrow 11.00$, $\mathrm{p}=0.172$ ) (Table 3, Figure 2). There was significant improvement on subjective memory by Subjective Memory Complaints Questionnaire (SMCQ) in intervention group (place- 
bo: $5.57 \rightarrow 4.83$, intervention group: $6.00 \rightarrow 4.24, \mathrm{p}=0.043$ ) (Table 3, Figure 3).

\section{Safety}

We evaluated complete blood cell counts (CBCs), blood chemistry (BC), and urine analysis (UA) at baseline and 12 weeks. No adverse event was observed in CBC parameters [white blood cell (WBC) count, red blood cell (RBC) count, hemoglobin $(\mathrm{Hb})$ level, hematocrit $(\mathrm{Ht})$, and platelet $(\mathrm{Plt})$ count], liver function [aspartate aminotransferase (AST), alanine aminotransferase (ALT), total bilirubin, and lactate dehydrogenase $(\mathrm{LDH})$ ], renal function [urea nitrogen (BUN), creatinine $(\mathrm{Cr})$ ], electrolytes [sodium $(\mathrm{Na})$, potassium $(\mathrm{K})$, chloride $(\mathrm{Cl})$ ], albumin, total protein, fasting glucose, and UA after taking black rice extract or placebo. Adverse event after taking black rice extract or placebo was not reported by the participants during trial.

\section{DISCUSSION}

This study found that C3G-rich Oryza sativa L. extract improves subjective memory. Also, there was no reported adverse event of C3G-rich Oryza sativa L. extract. However, this study did not find objective cognitive improvements by ADAS-cog nor CERAD-K following 12 weeks of consuming black rice extract. However, we did show a trend to improve cognitive function in the ADAS-cog score in the intervention group compared to in placebo group. After excluding participants with APOE4 gene, this trend for improvement was strengthened, potentially because participants with APOE4 genes may have other pathologies, such as the amyloid accumulation of brain or functional change of brain network unlike the participants without APOE4 gene. ${ }^{29}$

Flavonoids are molecules that have strong evidences for biological function in the brain. Flavonoids such as flavanone, anthocyanins, C3G and pelargonidin-3-glucoside (P3G)

Table 2. Lipid profiles and blood pressure (BP) by group at baseline and 12 weeks

\begin{tabular}{|c|c|c|c|c|c|}
\hline & \multicolumn{2}{|c|}{ Baseline } & \multicolumn{2}{|c|}{12 weeks } & \multirow{2}{*}{$\mathrm{p}$ value } \\
\hline & Placebo & Intervention & Placebo & Intervention & \\
\hline Total cholesterol (mg/dL) & $177.30(32.48)$ & $182.48(24.07)$ & $173.30(37.95)$ & $174.60(29.16)$ & 0.60 \\
\hline Triglyceride (mg/dL) & $144.87(83.24)$ & $128.12(58.01)$ & $150.87(78.74)$ & $145.92(82.54)$ & 0.62 \\
\hline $\mathrm{HDL}(\mathrm{mg} / \mathrm{dL})$ & $51.30(12.69)$ & $53.31(13.54)$ & $49.82(12.11)$ & $52.41(12.58)$ & 0.84 \\
\hline $\mathrm{LDL}(\mathrm{mg} / \mathrm{dL})$ & $104.52(36.09)$ & $108.64(21.80)$ & $100.74(32.05)$ & $105.04(28.13)$ & 0.98 \\
\hline Diastolic BP (mm/Hg) & $73.43(8.72)$ & $77.60(6.87)$ & $70.13(8.31)$ & $73.36(10.31)$ & 0.91 \\
\hline Systolic BP (mm/Hg) & $132.30(15.69)$ & $128.16(10.55)$ & $124.61(12.76)$ & $127.00(16.25)$ & 0.10 \\
\hline
\end{tabular}

Data are presented as the mean (SD)

Table 3. Neuropsychological test scores by group at baseline and 12 weeks

\begin{tabular}{|c|c|c|c|c|c|}
\hline & \multicolumn{2}{|c|}{ Baseline } & \multicolumn{2}{|c|}{12 weeks } & \multirow{2}{*}{$\mathrm{p}$ value } \\
\hline & Placebo & Intervention & Placebo & Intervention & \\
\hline ADAS-cog & $12.48(3.07)$ & $12.96(3.50)$ & $11.70(3.34)$ & $11.20(3.62)$ & 0.27 \\
\hline CERAD-K total score & $66.39(7.14)$ & $64.56(8.78)$ & $74.13(7.03)$ & $71.40(10.44)$ & 0.59 \\
\hline Verbal Fluency (VF) & $13.35(3.21)$ & $12.80(3.35)$ & $14.48(3.13)$ & $13.52(4.09)$ & 0.63 \\
\hline 15-item Boston Naming Test (BNT) & $11.57(1.70)$ & $11.52(2.45)$ & $12.52(1.59)$ & $12.52(1.98)$ & 0.90 \\
\hline Mini Mental Status Examination (MMSE) & $26.04(1.87)$ & $25.80(2.65)$ & $26.26(2.60)$ & $25.32(3.00)$ & 0.26 \\
\hline Word List Memory (WLM) & $17.39(2.62)$ & $16.88(2.70)$ & $20.65(3.10)$ & $19.60(4.45)$ & 0.57 \\
\hline Constructional Praxis (CP) & $10.13(1.22)$ & $9.48(1.50)$ & $10.26(1.36)$ & $9.76(1.42)$ & 0.69 \\
\hline Word List Recall (WLR) & $5.30(0.93)$ & $5.28(1.60)$ & $6.78(1.28)$ & $6.60(1.76)$ & 0.72 \\
\hline Word List Recognition (WLRc) & $8.65(1.50)$ & $8.60(1.50)$ & $9.43(0.66)$ & $9.40(0.87)$ & 0.96 \\
\hline Constructional Recall (CR) & $6.48(2.45)$ & $6.04(2.56)$ & $8.39(1.92)$ & $7.88(2.30)$ & 0.92 \\
\hline Trail making A (seconds) & $54.91(17.33)$ & $63.44(24.24)$ & $46.52(17.55)$ & $61.88(31.05)$ & 0.24 \\
\hline Trail making B (seconds) & $186.17(83.04)$ & $215.13(86.89)$ & $159.52(84.79)$ & $194.58(91.27)$ & 0.77 \\
\hline SMCQ & $5.57(3.75)$ & $6.00(2.77)$ & $4.83(3.55)$ & $4.24(2.40)$ & 0.04 \\
\hline
\end{tabular}

Data are presented as the mean (SD). CERAD-K total score $=\mathrm{VF}+\mathrm{BNT}+\mathrm{WLM}+\mathrm{CP}+\mathrm{WLR}+\mathrm{WLRc}$. ADAS-cog: Alzheimer's Disease Assessment Scale-cognitive subscale, CERAD-K: Korean version of the Consortium to Establish a Registry for Alzheimer's disease 
are able to traverse the $\mathrm{BBB} .{ }^{30-32}$ There are emerging evidences to suggest that flavonoids may be capable of counteracting such neuronal injury, thereby delaying the progression of

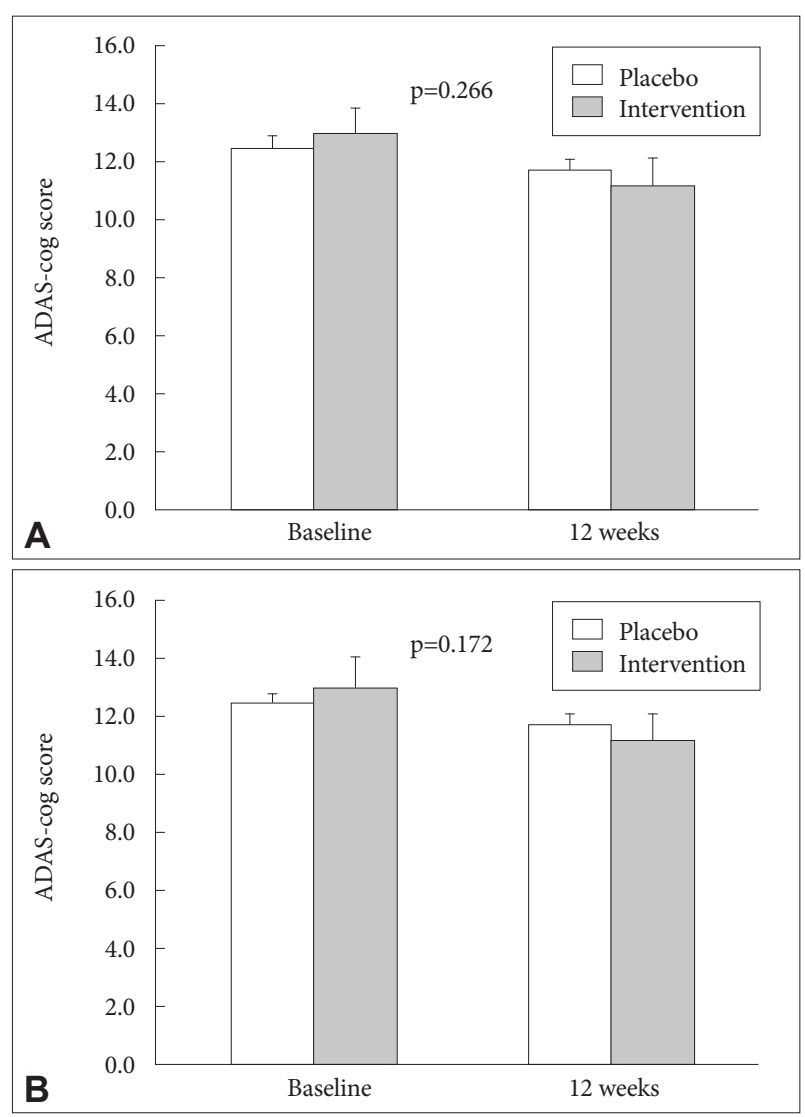

Figure 2. ADAS-cog score changes. A: A trend for improvement in ADAS-cog score (placebo: $12.48 \rightarrow 11.70$, intervention group: $12.96 \rightarrow 11.20, p=0.266, N=48)$. B: After excluding participant with APOE4 gene $(\mathrm{N}=5)$, the trend for improvement in ADAS-cog score (placebo: $12.38 \rightarrow 11.67$, intervention group: $13.00 \rightarrow 11.00$, $p=0.172, N=43$ ). ADAS-cog: Alzheimer's Disease Assessment Scale-cognitive subscale.

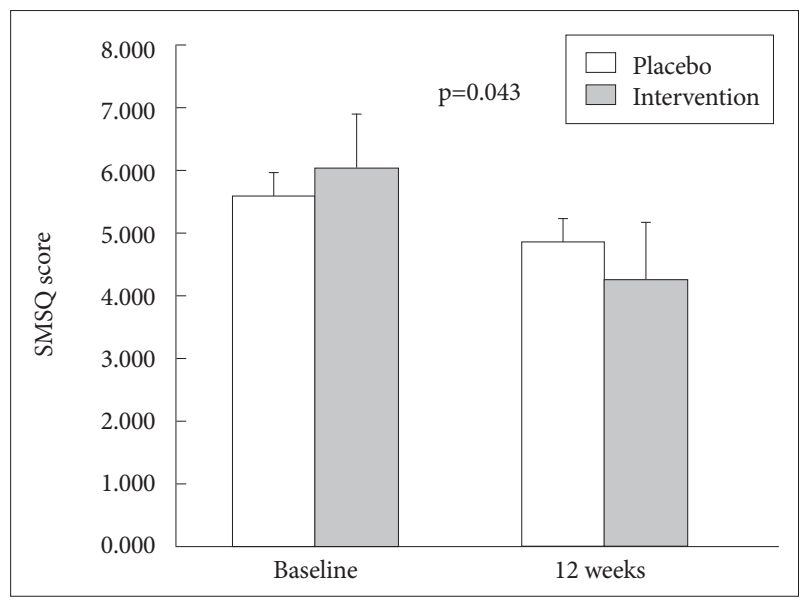

Figure 3. Subjective Memory Complaints Questionnaire (SMCQ) score changes. Statistical significant improvement on SMCQ score in intervention group $(p=0.043)$. disease pathologies. There are some theories about the mechanism of action of flavonoids on cognition. For example, flavonoids have the potential to act on the cognitive processes by inhibition of both the apoptosis in neurons and a reduction of neuroinflammatory reactions in microglia in the brain. ${ }^{33-35}$ Flavonoids also may activate synaptic signaling, ${ }^{36}$ increase cerebrovascular blood flow, and initiate neurogenesis. ${ }^{37}$ These induced changes in the neuronal architecture are required for cognition, ${ }^{38}$ therefore there is intense interest in the flavononids' effects to prevent neurodegeneration and brain aging, and enhance memory and cognition. Additionally, flavanols, anthocyanins, and flavanones all have demonstrated potential of cognitive improvement. ${ }^{39,40}$ Among these, several clinical trials on anthocyanin have been conducted, however, these studies have yielded mixed results and therefore, there is a need for further studies to determine any cognitive benefits that may be seen from anthocyanin.

Present study shows no significant differences in blood pressure and blood lipid profile. These findings are consistent with previous findings. ${ }^{9,15}$ In contrast, other studies demonstrated that flavonoids consumption was effective in decreasing blood pressure or lipid profiles. ${ }^{10,12,14}$ Furthermore, in recent years, several studies have shown that supplementation of Oryza sativa L. extract or anthocyanins resulted in a decrease in serum triglyceride, total cholesterol, and non-HDL cholesterol in vivo and in vitro. ${ }^{23,41,42}$ Further clinical trials are needed to study the direct effect of Oryza sativa L. on lipid and blood pressure.

Our study has several limitations. First, our study has relatively small sample size and short intervention length (12 weeks). A short time frame limits our ability for observations regarding changes in cognitive improvement. Second, intake of black rice itself may have more of an effect on cognitive function than intake of extract. In our lab, researchers found that black rice contained high concentration of paeonidin3-glucoside (P3G) as well as C3G, however in the black rice extract used in this study, the amount of P3G were negligible. If we used black rice itself rather than extract, the synergy between P3G and C3G may be increased. Third, our study was designed to give a smaller amount of $\mathrm{C} 3 \mathrm{G}$ compared to other clinical studies. ${ }^{9-11}$ Greater C3G consumption may have resulted in more potent antioxidant and phytochemical effects. Although the dosage to be given to the humans was determined by prior animal study, we concluded that the total amount of C3G was probably too small to induce cognitive improvement in the older adult with subjective memory impairment of the present study. Fourth, while we initially educated participants to limit their consumption of flavonoid-rich foods during this trial, strict control of their diets was not attempted. Thus, it is possible that intake of other 
flavonoids rich foods during the trial may have confounded the current results. Fifth, this study did not include inflammation markers such as C-reactive protein in hematological tests. Finally, participants in our study are not demented, but SMCQ mean have wide range. In spite of our effort to exclude major depressive disorders, subsyndromal depression might affect the results.

Despite of these limitations, this is the first clinical trial examining the association between cognitive function and anthocyanin of black rice. Furthermore, our study proved effect to improve subjective memory and the safety of Oryza sativa L. extract. The results may be informative of the possible effectiveness of the C3G-rich Oryza sativa L. on cognitive function. Although the objective cognitive outcomes were not statistically significant, the C3G-rich Oryza sativa L. studied also provides a possible alternative for the management of cognitive impairment. Also, we found that C3G-rich Oryza sativa L. extract improves subjective memory in this study, C3G-rich Oryza sativa L. extract has a potential as health functional food who are concerned about memory impairment or have symptoms of subjective memory impairment. However, it is not known whether C3G is effective in patients with mild cognitive impairment or dementia because the clinical study has not been conducted.

We plan future studies to support the findings and to address the limitations of the current study. Based on this research, we hope that the research on the effect of the C3G-rich Oryza sativa $\mathrm{L}$. on cognitive function will be actively carried out.

\section{Acknowledgments}

We would like to thank all the authors of the included studies. This study was supported by a grant from the BioGreen 21 Program (No. PJ00983001 2013), Rural Development Administration, Republic of Korea, and by the Ministry of Trade, Industry \& Energy (MOTIE, Korea) under Industry Technology Innovation Program (No. 10062378).

\section{Conflicts of Interest}

The authors have no potential conflicts of interest to disclose.

\section{Author Contributions}

Conceptualization: Chang Uk Lee, Shin Hee Yoon, Kee Dong Yoon. Data curation: Soo Hyun Joo, Changtae Hahn, Hyun Kook Lim. Formal analysis: Soo Hyun Joo. Validation: Chang Uk Lee. Writing-original draft: Soo Hyun Joo, Changtae Hahn. Writing_-review \& editing: Changtae Hahn, Chang Uk Lee.

\section{ORCID iDs}

$\begin{array}{ll}\text { Chang Uk Lee } & \text { https://orcid.org/0000-0001-6398-7330 } \\ \text { Soo Hyun Joo } & \text { https://orcid.org/0000-0003-1390-3623 }\end{array}$

\section{REFERENCES}

1. Agostinho P, Cunha RA, Oliveira C. Neuroinflammation, oxidative stress and the pathogenesis of Alzheimer's disease. Curr Pharm Des 2010;16:2766-2778.

2. Verdile G, Keane KN, Cruzat VF, Medic S, Sabale M, Rowles J, et al.
Inflammation and oxidative stress: the molecular connectivity between insulin resistance, obesity, and Alzheimer's disease. Mediators Inflamm 2015;2015:105828.

3. Zhao Y, Zhao B. Oxidative stress and the pathogenesis of Alzheimer's disease. Oxid Med Cell Longev 2013;2013:316523.

4. Tarozzi A, Merlicco A, Morroni F, Franco F, Cantelli-Forti G, Teti G, et al. Cyanidin 3-O-glucopyranoside protects and rescues SH-SY5Y cells against amyloid-beta peptide-induced toxicity. Neuroreport 2008; 19:1483-1486

5. Bhuiyan MI, Kim HB, Kim SY, Cho KO. The neuroprotective potential of Cyanidin-3-glucoside fraction extracted from Mulberry following oxygen-glucose deprivation. Korean J Physiol Pharmacol 2011;15:353-361.

6. Yang JS, Perveen S, Ha TJ, Kim SY, Yoon SH. Cyanidin-3-glucoside inhibits glutamate-induced $\mathrm{Zn} 2+$ signaling and neuronal cell death in cultured rat hippocampal neurons by inhibiting Ca2+-induced mitochondrial depolarization and formation of reactive oxygen species. Brain Res 2015;1606:9-20.

7. Ke Z, Liu Y, Wang X, Fan Z, Chen G, Xu M, et al. Cyanidin-3-glucoside ameliorates ethanol neurotoxicity in the developing brain. J Neurosci Res 2011;89:1676-1684.

8. Kang TH, Hur JY, Kim HB, Ryu JH, Kim SY. Neuroprotective effects of the cyanidin-3-O-beta-d-glucopyranoside isolated from mulberry fruit against cerebral ischemia. Neurosci Lett 2006;391:122-126.

9. Krikorian R, Boespflug EL, Fleck DE, Stein AL, Wightman JD, Shidler $\mathrm{MD}$, et al. Concord grape juice supplementation and neurocognitive function in human aging. J Agric Food Chem 2012;60:5736-5742.

10. Kent K, Charlton K, Roodenrys S, Batterham M, Potter J, Traynor V, et al. Consumption of anthocyanin-rich cherry juice for 12 weeks improves memory and cognition in older adults with mild-to-moderate dementia. Eur J Nutr 2017;56:333-341.

11. Krikorian R, Shidler MD, Nash TA, Kalt W, Vinqvist-Tymchuk MR, Shukitt-Hale B, et al. Blueberry supplementation improves memory in older adults. J Agric Food Chem 2010;58:3996-4000.

12. Desideri G, Kwik-Uribe C, Grassi D, Necozione S, Ghiadoni L, Mastroiacovo D, et al. Benefits in cognitive function, blood pressure, and insulin resistance through cocoa flavanol consumption in elderly subjects with mild cognitive impairment: the Cocoa, Cognition, and Aging (CoCoA) Study. Hypertension 2012;60:794-801.

13. Brickman AM, Khan UA, Provenzano FA, Yeung LK, Suzuki W, Schroeter $\mathrm{H}$, et al. Enhancing dentate gyrus function with dietary flavanols improves cognition in older adults. Nat Neurosci 2014;17:1798-1803.

14. Mastroiacovo D, Kwik-Uribe C, Grassi D, Necozione S, Raffaele A, Pistacchio L, et al. Cocoa flavanol consumption improves cognitive function, blood pressure control, and metabolic profile in elderly subjects: the Cocoa, Cognition, and Aging ( $\mathrm{CoCoA})$ Study--a randomized controlled trial. Am J Clin Nutr 2015;101:538-548.

15. Crews WD Jr, Harrison DW, Wright JW. A double-blind, placebo-controlled, randomized trial of the effects of dark chocolate and cocoa on variables associated with neuropsychological functioning and cardiovascular health: clinical findings from a sample of healthy, cognitively intact older adults. Am J Clin Nutr 2008;87:872-880.

16. Limtrakul P, Yodkeeree S, Pitchakarn P, Punfa W. Suppression of Inflammatory Responses by Black Rice Extract in RAW 264.7 Macrophage Cells via Downregulation of NF-kB and AP-1 Signaling Pathways. Asian Pac J Cancer Prev 2015;16:4277-4283.

17. Jun HI, Shin JW, Song GS, Kim YS. Isolation and identification of phenolic antioxidants in black rice bran. J Food Sci 2015;80:C262-268.

18. Tang Y, Cai W, Xu B. From rice bag to table: fate of phenolic chemical compositions and antioxidant activities in waxy and non-waxy black rice during home cooking. Food Chem 2016;191:81-90.

19. Zaupa M, Calani L, Del Rio D, Brighenti F, Pellegrini N. Characterization of total antioxidant capacity and (poly)phenolic compounds of differently pigmented rice varieties and their changes during domestic cooking. Food Chem 2015;187:338-347.

20. Hui C, Bin Y, Xiaoping Y, Long Y, Chunye C, Mantian M, et al. Antican- 
cer activities of an anthocyanin-rich extract from black rice against breast cancer cells in vitro and in vivo. Nutr Cancer 2010;62:1128-1136.

21. Luo LP, Han B, Yu XP, Chen XY, Zhou J, Chen W, et al. Anti-metastasis activity of black rice anthocyanins against breast cancer: analyses using an ErbB2 positive breast cancer cell line and tumoral xenograft model. Asian Pac J Cancer Prev 2014;15:6219-6225.

22. Chen XY, Zhou J, Luo LP, Han B, Li F, Chen JY, et al. Black rice anthocyanins suppress metastasis of breast cancer cells by targeting RAS/ RAF/MAPK pathway. Biomed Res Int 2015;2015:414250.

23. Yao SL, Xu Y, Zhang YY, Lu YH. Black rice and anthocyanins induce inhibition of cholesterol absorption in vitro. Food Funct 2013;4:1602-1608.

24. Um MY, Ahn J, Ha TY. Hypolipidaemic effects of cyanidin 3-glucoside rich extract from black rice through regulating hepatic lipogenic enzyme activities. J Sci Food Agric 2013;93:3126-3128.

25. Salgado JM, Oliveira AG, Mansi DN, Donado-Pestana CM, Bastos CR, Marcondes FK. The role of black rice (Oryza sativa L.) in the control of hypercholesterolemia in rats. J Med Food 2010;13:1355-1362.

26. Nakamura S, Hara T, Joh T, Kobayashi A, Yamazaki A, Kasuga K, et al. Effects of super-hard rice bread blended with black rice bran on amyloid beta peptide production and abrupt increase in postprandial blood glucose levels in mice. Biosci Biotechnol Biochem 2017;81:323-334.

27. Jeon H, Choi J, Choi S, Lee C, Yoon S, Kim J, et al. Rapid isolation of Cyanidin 3-Glucoside and Peonidin 3-Glucoside from black rice (Oryza sativa) using high-performance countercurrent chromatography and reversed-phase column chromatography. Nat Prod Sci 2015;21:30-33.

28. Youn JC, Kim KW, Lee DY, Jhoo JH, Lee SB, Park JH, et al. Development of the subjective memory complaints questionnaire. Dement Geriatr Cogn Disord 2009;27:310-317.

29. Castellano JM, Kim J, Stewart FR, Jiang H, DeMattos RB, Patterson BW, et al. Human apoE isoforms differentially regulate brain amyloid- $\beta$ peptide clearance. Sci Transl Med 2011;3:89ra57.

30. Youdim KA, Dobbie MS, Kuhnle G, Proteggente AR, Abbott NJ, RiceEvans C. Interaction between flavonoids and the blood-brain barrier: in vitro studies. J Neurochem 2003;85:180-192.
31. Youdim KA, Shukitt-Hale B, Joseph JA. Flavonoids and the brain: interactions at the blood-brain barrier and their physiological effects on the central nervous system. Free Radic Biol Med 2004;37:1683-1693.

32. Youdim KA, Qaiser MZ, Begley DJ, Rice-Evans CA, Abbott NJ. Flavonoid permeability across an in situ model of the blood-brain barrier. Free Radic Biol Med 2004;36:592-604.

33. McGeer EG, McGeer PL. Inflammatory processes in Alzheimer's disease. Prog Neuropsychopharmacol Biol Psychiatry 2003;27:741-749.

34. Jellinger KA. Cell death mechanisms in neurodegeneration. J Cell Mol Med 2001;5:1-17.

35. Spires TL, Hannan AJ. Nature, nurture and neurology: gene-environment interactions in neurodegenerative disease. FEBS Anniversary Prize Lecture delivered on 27 June 2004 at the 29th FEBS Congress in Warsaw. FEBS J 2005;272:2347-2361.

36. Joseph JA, Shukitt-Hale B, Lau FC. Fruit polyphenols and their effects on neuronal signaling and behavior in senescence. Ann N Y Acad Sci 2007;1100:470-485.

37. Commenges D, Scotet V, Renaud S, Jacqmin-Gadda H, Barberger-Gateau P, Dartigues JF. Intake of flavonoids and risk of dementia. Eur J Epidemiol 2000;16:357-363.

38. Spencer JP. The impact of fruit flavonoids on memory and cognition. Br J Nutr 2010;104 (Suppl 3):S40-S47.

39. Spencer JP. Food for thought: the role of dietary flavonoids in enhancing human memory, learning and neuro-cognitive performance. Proc Nutr Soc 2008;67:238-252.

40. Spencer JP. Flavonoids: modulators of brain function? Br J Nutr 2008;99 E (Suppl 1):ES60-ES77.

41. Wang D, Xia M, Gao S, Li D, Zhang Y, Jin T, et al. Cyanidin-3-O-betaglucoside upregulates hepatic cholesterol 7alpha-hydroxylase expression and reduces hypercholesterolemia in mice. Mol Nutr Food Res 2012;56:610-621.

42. Xia X, Ling W, Ma J, Xia M, Hou M, Wang Q, et al. An anthocyaninrich extract from black rice enhances atherosclerotic plaque stabilization in apolipoprotein E-deficient mice. J Nutr 2006;136:2220-2225. 